\title{
Association between cardiac conduction defect and nonalcoholic fatty liver disease: a systematic review and meta-analysis
}

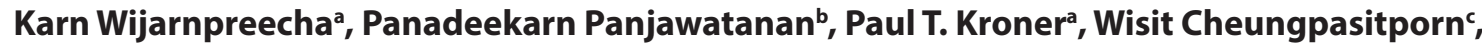 \\ Patompong Ungprasert ${ }^{d}$
}

Mayo Clinic College of Medicine, Jacksonville, Florida, USA; Bassett Medical Center, Cooperstown, NY, USA; University of Mississippi Medical Center, Jackson, Mississippi, USA; Siriraj Hospital, Mahidol University, Bangkok, Thailand

\begin{abstract}
Background Cardiovascular disease is a common comorbidity of patients with nonalcoholic fatty liver disease (NAFLD), particularly coronary artery disease and congestive heart failure. However, the relation between NAFLD and cardiac conduction defects has not been well studied. This systematic review and meta-analysis was conducted to identify all available studies on this association and summarize their results.

Methods A comprehensive literature review was conducted using MEDLINE and EMBASE databases through June 2020 to identify studies that compared the risk of a cardiac conduction defect among patients with NAFLD versus those without. Effect estimates from each study were extracted and combined using the random-effect, generic inverse variance method of DerSimonian and Laird.

Results Three cross-sectional studies with 3651 participants fulfilled the eligibility criteria and were included in this meta-analysis. The risk of a cardiac conduction defect was significantly higher among patients with NAFLD than in those without NAFLD, with a pooled odds ratio of 5.17 (95\% confidence interval 1.34-20.01; $I^{2}$ 96\%).

Conclusion A significantly greater risk of cardiac conduction defects among patients with NAFLD was observed in this meta-analysis. How this risk should be managed in clinical practice requires further investigation.
\end{abstract}

Keywords Nonalcoholic fatty liver disease, nonalcoholic steatohepatitis, heart block, cardiac conduction defect, meta-analysis

Ann Gastroenterol 2020; 33 (6): 1-9

\section{Introduction}

Nonalcoholic fatty liver disease (NAFLD) is defined as the presence of more than $5 \%$ of hepatic fat accumulation without

${ }^{a}$ Division of Gastroenterology and Hepatology, Mayo Clinic College of Medicine, Jacksonville, Florida, USA (Karn Wijarnpreecha, Paul T. Kroner); ${ }^{b}$ Department of Internal Medicine, Bassett Medical Center, Cooperstown, NY, USA (Panadeekarn Panjawatanan); ${ }^{\mathrm{C}}$ Department of Medicine, Division of Nephrology, University of Mississippi Medical Center, Jackson, Mississippi, USA (Wisit Cheungpasitporn); ${ }^{\mathrm{C}}$ Clinical Epidemiology Unit, Department of Research and Development, Faculty of Medicine, Siriraj Hospital, Mahidol University, Bangkok, Thailand (Patompong Ungprasert)

\section{Conflict of Interest: None}

Correspondence to: Karn Wijarnpreecha, MD, 4500 San Pablo Rd S, Jacksonville, Florida, 32224 USA, e-mail: dr.karn.wi@gmail.com

Received 31 March 2020; accepted 26 June 2020;

published online 16 September 2020

DOI: https://doi.org/10.20524/aog.2020.0535 a history of excessive alcohol consumption or any secondary causes of liver disease [1]. A recent meta-analysis has estimated the pooled incidence of NAFLD to be approximately 50 per 1000 person-years in Asia and approximately 25 per 1000 person-years in Europe [2-4]. Several metabolic disorders, such as diabetes mellitus, obesity, dyslipidemia, hypertension and hyperuricemia, are more common among patients with NAFLD [5-9]. The relationship between NAFLD and these disorders is bidirectional and is linked by insulin resistance and chronic inflammation [10].

Cardiovascular disease is another common associated disorder among patients with NAFLD [11,12], particularly coronary artery disease and congestive heart failure, as has been observed by several epidemiologic studies [13-16]. Patients with NAFLD may also be at an increased risk of cardiac conduction defects, although the evidence for this particular type of cardiovascular disease is still relatively limited [17-19]. This systematic review and meta-analysis was conducted to identify all observational studies that investigated the risk of cardiac conduction defects among patients with 
NAFLD versus those without and to summarize their results together to better characterize this risk.

\section{Materials and methods}

\section{Information sources and search strategy}

We conducted a comprehensive literature review using the MEDLINE and EMBASE databases from inception to June 2020 and isolated all original studies relevant to the association between NAFLD and cardiac conduction defect. The comprehensive literature search was conducted by 3 investigators (KW, PP, and PU) individually, using search terms that included the following: "nonalcoholic fatty liver disease", "nonalcoholic steatohepatitis", "bundle branch block", "heart block", and "cardiac conduction defect", as described in online supplementary data 1 . No language limitation was applied. In addition, a manual search was performed for potentially valid studies using existing references cited in selected articles. This meta-analysis followed the PRISMA (Preferred Reporting Items for Systematic Reviews and Meta-Analysis) statement provided as online supplementary data 2 .

\section{Selection criteria}

Eligible studies had to be cross-sectional, case-control or cohort studies that investigated the relationship between NAFLD and cardiac conduction defects. They had to provide effect estimates-odds ratios (OR), relative risks, hazard ratios, or standardized incidence ratio-with $95 \%$ confidence intervals (CI). Inclusion was not limited by study size. In the case of overlap, we included the studies with the most comprehensive data.

Three investigators (KW, PP, and PU) individually reviewed selected articles for their eligibility. Disagreement was resolved by conference with all investigators to reach a mutual final decision. The quality of case-control and cohort studies was assessed using the Newcastle-Ottawa quality scale. The modified version of this scale as described by Herzog et al was used for cross-sectional studies [20].

\section{Data abstraction}

A specially designed table was used to collect the following data from each study: study title, name of first author, publication year, country or countries of origin of research, number of subjects, subjects' demographic data, methods used to identify and verify NAFLD and cardiac conduction defect, 95\%CI of adjusted effect estimates with covariates in multivariable analysis.

To ensure accuracy, 2 investigators (KW and PP) individually performed this data extraction process. The data table was finalized by the senior investigator (PU).

\section{Statistical analysis}

Data analysis was performed using the Review Manager 5.3 software from the Cochrane Collaboration (London, United Kingdom). The generic inverse variance method of DerSimonian and Laird was used to adjust point estimates from each study. This method weighted each study for the pooled analysis based on its variance [21]. A random-effect model was used, rather than a fixed-effect model, as we expected that the included studies would be somewhat different from each other with respect to the background populations and the methods used to diagnose NAFLD and cardiac conduction defect. Cochran's Q test and $I^{2}$ statistic were used to determine heterogeneity between the studies. Four intervals of $I^{2}$ were used: less than or equal to $25 \%$ represents insignificant heterogeneity; $26-50 \%$ represents low heterogeneity; $51-75 \%$ represents moderate heterogeneity; and more than $75 \%$ represents high heterogeneity [22].

\section{Results}

Two hundred twenty-nine articles were initially identified using the described search strategy (95 articles from Medline and 134 articles from EMBASE). After the exclusion of 90 duplicated articles, 139 articles underwent title and abstract review. One hundred and twenty articles were excluded at this stage since they were case reports, case series, correspondence, review articles, in vitro studies, animal studies or interventional studies, leaving 19 articles for full-text review. Sixteen of these were excluded after the full-length review as they did not report the association of interest. Finally, 3 cross-sectional studies [17-19] with 3651 participants were included in the final analysis. A flowchart showing the literature search, review and selection process is shown in Fig. 1. The study characteristics and quality assessment using the modified Newcastle-Ottawa scale are presented in Table 1. It should be noted that the interobserver reliability for the quality assessment was high, with a kappa statistics of 0.77 .

\section{Association between NAFLD and cardiac conduction defect}

The pooled analysis found a significantly greater risk of a cardiac conduction defect among patients with NAFLD, with a pooled OR of 5.17 (95\%CI 1.34-20.01), as demonstrated in Fig. 2. The heterogeneity between the studies was high, with an $I^{2}$ of $96 \%$.

\section{Evaluation for publication bias}

Evaluation for publication bias was not performed as the number of included studies was too small. 


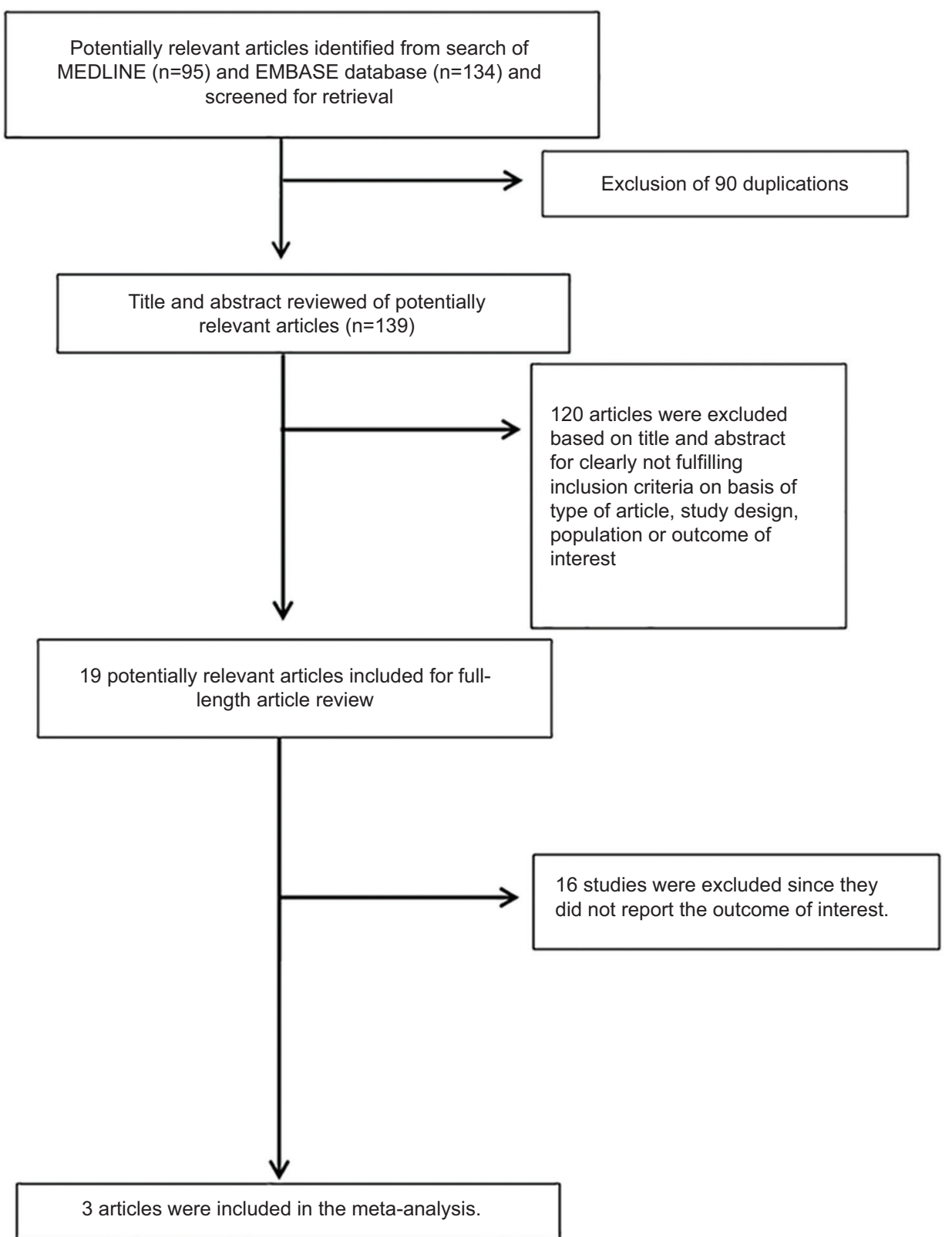

Figure 1 Literature review process

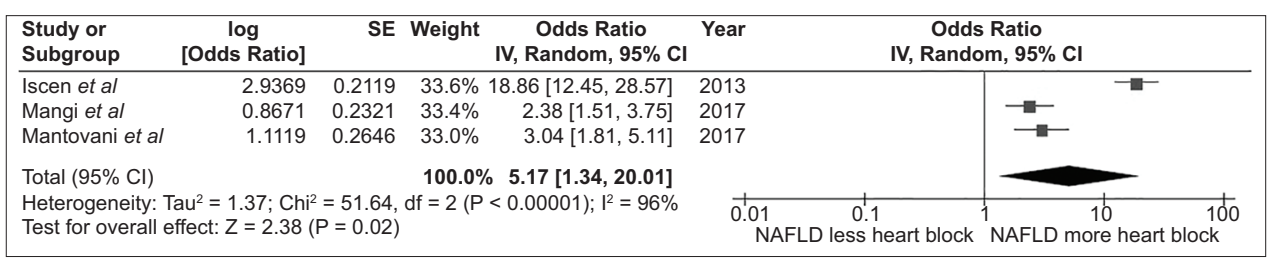

Figure 2 Forest plot of all studies

NAFLD, nonalcoholic fatty liver disease; CI, confidence interval; $d f$, degrees of freedom

\section{Discussion}

This study is the first systematic review and meta-analysis that comprehensively combined the data from all available studies on the association between NAFLD and cardiac conduction defect. The pooled analysis found an approximately 5 -fold greater risk of cardiac conduction defects among patients with NAFLD compared to individuals without. The 
Table 1 Main characteristics of the studies included in this meta-analysis

\begin{tabular}{|c|c|c|c|}
\hline Study & Iscen et al [17] & Mangi et al [18] & Mantovani et al [19] \\
\hline Country & Turkey & USA & Italy \\
\hline Study design & Cross-sectional study & Cross-sectional study & Cross-sectional study \\
\hline Year & 2013 & 2017 & 2017 \\
\hline $\begin{array}{l}\text { Total number of } \\
\text { participants }\end{array}$ & 2200 & 700 & 751 \\
\hline $\begin{array}{l}\text { Recruitment of } \\
\text { participants }\end{array}$ & $\begin{array}{l}\text { Participants were male who } \\
\text { underwent health screening } \\
\text { examination at Medical Check-up } \\
\text { Center, Turkey from March } 2012 \text { to } \\
\text { March 2013. Participants had ECG } \\
\text { and abdomen ultrasonography as } \\
\text { parts of their examinations. }\end{array}$ & $\begin{array}{l}\text { Participants were adult patients } \\
\text { aged } 18 \text { years and above admitted } \\
\text { to Orange Park Medical Center in } \\
\text { Florida from } 2009 \text { to } 2015 \text { and had } \\
\text { 1) ultrasonography and/or CT scan } \\
\text { of the abdomen and 2) ECG during } \\
\text { hospitalization. }\end{array}$ & $\begin{array}{l}\text { Participants were adult patients admitted at } \\
\text { the Verona University Hospital from } 2007 \\
\text { to } 2014 \text { and had 1) ultrasonography of the } \\
\text { abdomen and 2) ECG during hospitalization. }\end{array}$ \\
\hline Diagnosis of NAFLD & $\begin{array}{l}\text { Presence of hepatic steatosis on } \\
\text { ultrasonography of the abdomen }\end{array}$ & $\begin{array}{l}\text { Presence of hepatic steatosis on } \\
\text { ultrasonography or CT scan of the } \\
\text { abdomen without other causes }\end{array}$ & $\begin{array}{l}\text { Presence of hepatic steatosis on } \\
\text { ultrasonography of the abdomen without } \\
\text { other causes }\end{array}$ \\
\hline $\begin{array}{l}\text { Type of heart block } \\
\text { included in the study }\end{array}$ & RBBB & $\mathrm{AV}$ node block and $\mathrm{BBB}$ & AV node block, BBB and fascicular block \\
\hline $\begin{array}{l}\text { Confounder adjusted in } \\
\text { multivariate analysis }\end{array}$ & None & $\begin{array}{l}\text { Age, sex, DM, CHF and cardiac } \\
\text { hypertrophy }\end{array}$ & $\begin{array}{l}\text { Age, sex, BMI, duration of DM, } \mathrm{HbAlc} \text {, } \\
\text { eGFR-EPI, macroalbuminuria, hypertension } \\
\text { status, prior ischemic heart disease and mild- } \\
\text { to-moderate valvular heart disease, PAD, } \\
\text { DR, lower-extremity sensory neuropathy and } \\
\text { current use of statins or anti-platelet agents. }\end{array}$ \\
\hline $\begin{array}{l}\text { Quality assessment } \\
\text { (Newcastle-Ottawa } \\
\text { scale) }\end{array}$ & $\begin{array}{l}\text { Selection: } 3 \\
\text { Comparability: } 1 \\
\text { Outcome: } 3\end{array}$ & $\begin{array}{l}\text { Selection: } 3 \\
\text { Comparability: } 2 \\
\text { Outcome: } 4\end{array}$ & $\begin{array}{l}\text { Selection: } 3 \\
\text { Comparability: } 2 \\
\text { Outcome: } 4\end{array}$ \\
\hline
\end{tabular}

NAFLD, non-alcoholic fatty liver disease; RBBB, right bundle-branch block; $E C G$, electrocardiography; CT, computerized tomography; AV node, atrioventricular node; $B B B$, bundle-branch block; DM, diabetes mellitus; CHF, congestive heart failure; T2DM, type 2 diabetes mellitus; BMI, body mass index; HbA1C, hemoglobin A1c; eGFR-EPI, estimated glomerular filtration rate-epidemiology collaboration; PAD, peripheral artery disease; DR, diabetic retinopathy

reasons behind this increased risk are not well understood but there are some possible explanations.

The first explanation is related to the increased level of inflammatory cytokines among patients with NAFLD [23,24]. Deposition of adipose tissue in the liver induces low-grade systemic inflammation through the release of proinflammatory cytokines such as interleukin (IL)-1, IL-6, tumor necrosis factor, and transforming growth factor (TGF)- $\beta$. These cytokines are arrhythmogenic, as demonstrated by several studies $[25,26]$. For instance, in a rodent study, IL- $1 \beta$ was shown to prolong the repolarization phase and interfere with potassium and calcium fluxes, causing disturbance of cardiac conduction [27]. Another in vitro study found that an increased level of TGF- $\beta$ can induce fibrotic changes in cardiomyocytes, causing arrhythmias and conduction defects [28].

Second, fatty accumulation in the liver could be a marker of fatty deposition in other organ tissues, including myocardium and pericardium [29]. This ectopic fatty tissue acts as an electrical insulator, which may cause heart block and arrhythmia if it infiltrates the conduction system [18,30,31]. Moreover, this fatty infiltration can subsequently transform into fibrous tissue, which would further increase the severity of a conduction defect [32].
It is also possible that NAFLD does not directly cause conduction defects. The observed association could be a consequence of the increased risk of coronary artery disease [33] and heart failure [34] among patients with NAFLD, as both conditions can cause structural changes of the heart $[35,36]$. The current systematic review and meta-analysis could not exclude the role of these potential confounders, as the primary studies did not comprehensively adjust their effect estimates for them.

Even though we conducted a comprehensive literature search and retrieved high quality studies, as suggested by the high Newcastle-Ottawa scores, the study had some limitations and our results should be interpreted with caution. First, the statistical heterogeneity was high in this meta-analysis. We believe that the differences in the study population, the definition of cardiac conduction abnormality, and the variables used for adjustment in the multivariate analysis across the studies were the main source of the between-study variation. For instance, the study by Iscen et al [17] found only right bundle-branch block, a finding without any clinical significance in young adults. On the other hand, the other 2 studies included patients with cardiac conduction defects that are severe and need special cardiological management (i.e., first-degree block, Mobitz type 1 block, 
left bundle-branch block, bifascicular block and nonspecific intraventricular block in the study by Mangi et al [18], and first-degree atrioventricular block, second-degree block, thirddegree block, left bundle-branch block, right bundle-branch block, left anterior hemiblock and left posterior hemiblock in the study by Mantovani et al [19]). This would also make it difficult to determine the clinical implications of the observed association. Second, the temporal relationship between NAFLD and cardiac conduction defect could not be clearly established, given the cross-sectional nature of the included studies. It is still possible that the association between NAFLD and cardiac conduction is confounded by comorbidities, such as diabetes mellitus and other cardiovascular diseases, given that one of the 3 included studies did not adjust its effect estimate for any potential confounders. Further prospective cohort studies with comprehensive adjustment for potential confounders are still required. Third, we could not perform a publication bias analysis because of the limited number of studies included. Thus, publication bias in favor of studies with positive results may have been present. Fourth, none of the included studies provided data on subgroups of patients with nonalcoholic steatohepatitis. Further studies are still needed to investigate the risk in this specific subgroup.

In summary, the current study demonstrated a significantly greater risk of cardiac conduction defects among patients with NAFLD compared with individuals without. Physicians who provide care to patients with NAFLD should be aware of this association, since cardiovascular mortality is their most common cause of death. Nonetheless, further studies are still required to investigate whether the association is causal and to determine the role of screening and preventative measures in clinical practice.

\section{Summary Box}

\section{What is already known:}

- Cardiovascular disease is the most common cause of death in patients with non-alcoholic fatty liver disease (NAFLD)

- Previous studies showed that patients with NAFLD may have a higher risk of cardiac conduction defectss

- However, the results from those studies varied considerably

\section{What the new findings are:}

- This meta-analysis of 3 cross-sectional studies with 3651 participants showed that the risk of cardiac conduction defects among patients with NAFLD was 5 times higher than in those without NAFLD

- However, subgroup analysis for each type of cardiac conduction defect could not be performed because the data from the primary studies were limited

\section{References}

1. LaBrecque DR, Abbas Z, Anania F, et al; World Gastroenterology Organisation. World Gastroenterology Organisation global guidelines: nonalcoholic fatty liver disease and nonalcoholic steatohepatitis. J Clin Gastroenterol 2014;48:467-473.

2. Chalasani N, Younossi Z, Lavine JE, et al. The diagnosis and management of nonalcoholic fatty liver disease: Practice guidance from the American Association for the Study of Liver Diseases. Hepatology 2018;67:328-357.

3. Whalley S, Puvanachandra P, Desai A, Kennedy H. Hepatology outpatient service provision in secondary care: a study of liver disease incidence and resource costs. Clin Med (Lond) 2007;7:119-124.

4. Younossi ZM, Koenig AB, Abdelatif D, Fazel Y, Henry L, Wymer M. Global epidemiology of nonalcoholic fatty liver diseaseMeta-analytic assessment of prevalence, incidence, and outcomes. Hepatology 2016;64:73-84.

5. Byrne CD, Targher G. NAFLD: a multisystem disease. J Hepatol 2015;62:S47-S64.

6. Wijarnpreecha K, Panjawatan P, Lekuthai N, Thongprayoon C, Cheungpasitrorn W, Ungprasert P. Hyperuricemia and risk of nonalcoholic fatty liver disease: a meta-analysis. Liver Int 2017;37:906-918.

7. Wijarnpreecha K, Thongprayoon C, Edmonds PJ, Cheungpasitporn W. Associations of sugar- and artificially sweetened soda with nonalcoholic fatty liver disease: a systematic review and meta-analysis. QJM 2016;109:461-466.

8. Wijarnpreecha K, Thongprayoon C, Panjawatanan P, Ungprasert P. Short sleep duration and risk of nonalcoholic fatty liver disease: a systematic review and meta-analysis. $J$ Gastroenterol Hepatol 2016;31:1802-1807.

9. Wijarnpreecha K, Thongprayoon C, Ungprasert P. Coffee consumption and risk of nonalcoholic fatty liver disease: a systematic review and meta-analysis. Eur J Gastroenterol Hepatol 2017;29:e8-e12.

10. Wainwright P, Byrne CD. Bidirectional relationships and disconnects between NAFLD and features of the metabolic syndrome. Int J Mol Sci 2016;17:367.

11. Anstee QM, Mantovani A, Tilg H, Targher G. Risk of cardiomyopathy and cardiac arrhythmias in patients with nonalcoholic fatty liver disease. Nat Rev Gastroenterol Hepatol 2018;15:425-439.

12. Wijarnpreecha K, Boonpheng B, Thongprayoon C, Jaruvongvanich V, Ungprasert P. The association between nonalcoholic fatty liver disease and atrial fibrillation: a meta-analysis. Clin Res Hepatol Gastroenterol 2017;41:525-532.

13. Gummesson A, Strömberg U, Schmidt C, et al. Non-alcoholic fatty liver disease is a strong predictor of coronary artery calcification in metabolically healthy subjects: a cross-sectional, population-based study in middle-aged subjects. PLoS One 2018;13:e0202666.

14. Lee SB, Park GM, Lee JY, et al. Association between non-alcoholic fatty liver disease and subclinical coronary atherosclerosis: An observational cohort study. J Hepatol 2018;68:1018-1024.

15. Targher G, Day CP, Bonora E. Risk of cardiovascular disease in patients with nonalcoholic fatty liver disease. $N$ Engl J Med 2010;363:1341-1350.

16. Wong VW, Wong GL, Yip GW, et al. Coronary artery disease and cardiovascular outcomes in patients with non-alcoholic fatty liver disease. Gut 2011;60:1721-1727.

17. İscen S. RBBB is associated with an increased risk of NAFLD in young healthy individuals. Int J Cardiol 2013;168:4056-4057.

18. Mangi MA, Minhas AM, Rehman H, Pathan F, Liang H, Beidas S. Association of non-alcoholic fatty liver disease with conduction defects on electrocardiogram. Cureus 2017;9:e1107.

19. Mantovani A, Rigolon R, Pichiri I, et al. Nonalcoholic fatty liver 
disease is associated with an increased risk of heart block in hospitalized patients with type 2 diabetes mellitus. PLoS One 2017;12:e0185459.

20. Herzog R, Álvarez-Pasquin MJ, Díaz C, Del Barrio JL, Estrada JM, Gil. Are healthcare workers' intentions to vaccinate related to their knowledge, beliefs and attitudes? A systematic review. BMC Public Health 2013;13:154.

21. DerSimonian R, Laird N. Meta-analysis in clinical trials. Control Clin Trials 1986;7:177-188.

22. Higgins JP, Thompson SG, Deeks JJ, Altman DG. Measuring inconsistency in meta-analyses. BMJ 2003;327:557-560.

23. Anstee QM, Targher G, Day CP. Progression of NAFLD to diabetes mellitus, cardiovascular disease or cirrhosis. Nat Rev Gastroenterol Hepatol 2013;10:330-344.

24. Chung MK, Martin DO, Sprecher D, et al. C-reactive protein elevation in patients with atrial arrhythmias: inflammatory mechanisms and persistence of atrial fibrillation. Circulation 2001;104:2886-2891.

25. Braunersreuther V, Viviani GL, Mach F, Montecucco F. Role of cytokines and chemokines in non-alcoholic fatty liver disease. World J Gastroenterol 2012;18:727-735.

26. Dowman JK, Tomlinson JW, Newsome PN. Pathogenesis of nonalcoholic fatty liver disease. QJM 2010;103:71-83.

27. Monnerat G, Alarcón ML, Vasconcellos LR, et al. Macrophagedependent IL-1 $\beta$ production induces cardiac arrhythmias in diabetic mice. Nat Commun 2016;7:13344.

28. Salvarani N, Maguy A, De Simone SA, Miragoli M, Jousset F,
Rohr S. TGF-beta1 (Transforming Growth Factor-beta1) plays a pivotal role in cardiac myofibroblast arrhythmogenicity. Circ Arrhythm Electrophysiol 2017;10:e004567.

29. Gaggini M, Morelli M, Buzzigoli E, DeFronzo RA, Bugianesi E, Gastaldelli A. Non-alcoholic fatty liver disease (NAFLD) and its connection with insulin resistance, dyslipidemia, atherosclerosis and coronary heart disease. Nutrients 2013;5:1544-1560.

30. De Coster T, Claus P, Kazbanov IV, et al. Arrhythmogenicity of fibro-fatty infiltrations. Sci Rep 2018;8:2050.

31. Pantanowitz L. Fat infiltration in the heart. Heart 2001;85:253.

32. Haemers P, Hamdi H, Guedj K, et al. Atrial fibrillation is associated with the fibrotic remodelling of adipose tissue in the subepicardium of human and sheep atria. Eur Heart J 2017;38:53-61.

33. Arslan U, Türkoğlu S, Balcioğlu S, Tavil Y, Karakan T, Cengel A. Association between nonalcoholic fatty liver disease and coronary artery disease. Coron Artery Dis 2007;18:433-436.

34. Chung GE, Lee JH, Lee H, et al. Nonalcoholic fatty liver disease and advanced fibrosis are associated with left ventricular diastolic dysfunction. Atherosclerosis 2018;272:137-144.

35. Harper JR, Harley A, Hackel DB, Estes EH Jr. Coronary artery disease and major conduction disturbances. A pathologic study designed to correlate vascular and conduction system abnormalities with electrocardiogram. Am Heart J 1969;77:411-422.

36. Mentz RJ, Greiner MA, DeVore AD, et al. Ventricular conduction and long-term heart failure outcomes and mortality in African Americans: insights from the Jackson Heart Study. Circ Heart Fail 2015;8:243-251. 


\section{Supplementary material}

\section{Supplementary Data 1: Search Strategy}

\section{Database: Ovid MEDLINE}

1. Nonalcoholic fatty liver.mp. or exp Nonalcoholic fatty liver disease/

2. fatty liver.mp. or exp fatty liver/

3. nonalcoholic steatohepatitis.mp.

4. steatohepatitis.mp.

5. or/1-4

6. atrioventricular block.mp. or exp Atrioventricular Block/

7. heart muscle conduction disturbance.mp.

8. heart bundle branch block.mp.

9. heart right bundle branch block.mp.

10. heart left bundle branch block.mp.

11. heart left posterior bundle branch block.mp.

12. heart block.mp. or exp Heart Block/

13. complete heart block.mp.

14. heart sinoatrial block.mp.

15. or/5-14

\section{Database: EMBASE}

1. 'Nonalcoholic fatty liver' or 'Nonalcoholic fatty liver'/exp

2. 'fatty liver' or 'fatty liver'/exp

3. 'steatohepatitis' or 'steatohepatitis'/exp

4. or/1-3

5. 'atrioventricular block' or 'atrioventricular block'/exp

6. 'heart muscle conduction disturbance' or 'heart muscle conduction disturbance'/exp

7. 'heart bundle branch block' or 'heart bundle branch block'/exp

8. 'heart right bundle branch block' or 'heart right bundle branch block'/exp

9. 'heart left bundle branch block' or 'heart left bundle branch block'/ $\exp$

10. 'heart left posterior bundle branch block' or 'heart left posterior bundle branch block'/exp

11. 'heart block' or 'heart block'/exp

12. 'complete heart block' or 'complete heart block'/exp

13. 'heart sinoatrial block' or 'heart sinoatrial block'/exp

14. or $/ 5-13$

19. 4 and 14 
TITLE

\begin{tabular}{llll}
\hline Title & 1 & Identify the report as a systematic review, meta-analysis, or both & 1 \\
\hline ABSTRACT & & \\
\hline $\begin{array}{l}\text { Structured } \\
\text { summary }\end{array}$ & $\begin{array}{l}\text { Provide a structured summary including, as applicable: background; objectives; } \\
\text { data sources; study eligibility criteria, participants, and interventions; study } \\
\text { appraisal and synthesis methods; results; limitations; conclusions and implications } \\
\text { of key findings; systematic review registration number }\end{array}$ & 1 \\
\hline
\end{tabular}

\section{INTRODUCTION}

\begin{tabular}{llll}
\hline Rationale & 3 & Describe the rationale for the review in the context of what is already known & 1 \\
Objectives & 4 & $\begin{array}{l}\text { Provide an explicit statement of questions being addressed with reference to participants, } \\
\text { interventions, comparisons, outcomes, and study design (PICOS) }\end{array}$ & 1 \\
\hline
\end{tabular}

\section{METHODS}

\begin{tabular}{|c|c|c|c|}
\hline $\begin{array}{l}\text { Protocol and } \\
\text { registration }\end{array}$ & 5 & $\begin{array}{l}\text { Indicate if a review protocol exists, if and where it can be accessed (e.g., Web address), and, if } \\
\text { available, provide registration information including registration number }\end{array}$ & 2 \\
\hline $\begin{array}{l}\text { Eligibility } \\
\text { criteria }\end{array}$ & 6 & $\begin{array}{l}\text { Specify study characteristics (e.g., PICOS, length of follow-up) and report characteristics (e.g., } \\
\text { years considered, language, publication status) used as criteria for eligibility, giving rationale }\end{array}$ & 2 \\
\hline $\begin{array}{l}\text { Information } \\
\text { sources }\end{array}$ & 7 & $\begin{array}{l}\text { Describe all information sources (e.g., databases with dates of coverage, contact with study authors } \\
\text { to identify additional studies) in the search and date last searched }\end{array}$ & 2 \\
\hline Search & 8 & $\begin{array}{l}\text { Present full electronic search strategy for at least one database, including any limits used, such that } \\
\text { it could be repeated }\end{array}$ & $\begin{array}{l}2 \text { and supplementary } \\
\text { data } 1\end{array}$ \\
\hline Study selection & 9 & $\begin{array}{l}\text { State the process for selecting studies (i.e., screening, eligibility, included in systematic review, and, } \\
\text { if applicable, included in the meta-analysis) }\end{array}$ & $2-3$ \\
\hline $\begin{array}{l}\text { Data collection } \\
\text { process }\end{array}$ & 10 & $\begin{array}{l}\text { Describe method of data extraction from reports (e.g., piloted forms, independently, in duplicate) } \\
\text { and any processes for obtaining and confirming data from investigators }\end{array}$ & $2-3$ \\
\hline Data items & 11 & $\begin{array}{l}\text { List and define all variables for which data were sought (e.g., PICOS, funding sources) and any } \\
\text { assumptions and simplifications made }\end{array}$ & 2 \\
\hline $\begin{array}{l}\text { Risk of bias } \\
\text { in individual } \\
\text { studies }\end{array}$ & 12 & $\begin{array}{l}\text { Describe methods used for assessing risk of bias of individual studies (including specification of } \\
\text { whether this was done at the study or outcome level), and how this information is to be used in } \\
\text { any data synthesis }\end{array}$ & Table 1 \\
\hline $\begin{array}{l}\text { Summary } \\
\text { measures }\end{array}$ & 13 & State the principal summary measures (e.g., risk ratio, difference in means) & 2 \\
\hline $\begin{array}{l}\text { Synthesis of } \\
\text { results }\end{array}$ & 14 & $\begin{array}{l}\text { Describe the methods of handling data and combining results of studies, if done, including } \\
\text { measures of consistency (e.g., I2) for each meta-analysis }\end{array}$ & 2 \\
\hline $\begin{array}{l}\text { Risk of bias } \\
\text { across studies }\end{array}$ & 15 & $\begin{array}{l}\text { Specify any assessment of risk of bias that may affect the cumulative evidence (e.g., publication } \\
\text { bias, selective reporting within studies) }\end{array}$ & Not applicable \\
\hline $\begin{array}{l}\text { Additional } \\
\text { analyses }\end{array}$ & 16 & $\begin{array}{l}\text { Describe methods of additional analyses (e.g., sensitivity or subgroup analyses, meta-regression), } \\
\text { if done, indicating which were pre-specified }\end{array}$ & Not applicable \\
\hline
\end{tabular}

\section{RESULTS}

\begin{tabular}{|c|c|c|c|}
\hline Study selection & 17 & $\begin{array}{l}\text { Give numbers of studies screened, assessed for eligibility, and included in the review, with reasons } \\
\text { for exclusions at each stage, ideally with a flow diagram }\end{array}$ & $2-3$ \\
\hline $\begin{array}{l}\text { Study } \\
\text { characteristics }\end{array}$ & 18 & $\begin{array}{l}\text { For each study, present characteristics for which data were extracted (e.g., study size, PICOS, } \\
\text { follow-up period) and provide the citations }\end{array}$ & Table 1 \\
\hline $\begin{array}{l}\text { Risk of bias } \\
\text { within studies }\end{array}$ & 19 & Present data on risk of bias of each study and, if available, any outcome level assessment (see item 12) & Table 1 \\
\hline $\begin{array}{l}\text { Results of } \\
\text { individual } \\
\text { studies }\end{array}$ & 20 & $\begin{array}{l}\text { For all outcomes considered (benefits or harms), present, for each study: (a) simple } \\
\text { summary data for each intervention group (b) effect estimates and confidence intervals, ideally } \\
\text { with a forest plot }\end{array}$ & Figure 2 \\
\hline
\end{tabular}


Supplementary Data 2: (Continued)

\begin{tabular}{|c|c|c|c|}
\hline Section/topic & $\#$ & Checklist item & Reported on page \# \\
\hline $\begin{array}{l}\text { Synthesis of } \\
\text { results }\end{array}$ & 21 & $\begin{array}{l}\text { Present results of each meta-analysis done, including confidence intervals and measures of } \\
\text { consistency }\end{array}$ & 3 \\
\hline $\begin{array}{l}\text { Risk of bias } \\
\text { across studies }\end{array}$ & 22 & Present results of any assessment of risk of bias across studies (see Item 15) & Not applicable \\
\hline $\begin{array}{l}\text { Additional } \\
\text { analysis }\end{array}$ & 23 & $\begin{array}{l}\text { Give results of additional analyses, if done (e.g., sensitivity or subgroup analyses, meta-regression } \\
\text { [see Item 16]) }\end{array}$ & Not applicable \\
\hline
\end{tabular}

DISCUSSION

\begin{tabular}{|c|c|c|c|}
\hline $\begin{array}{l}\text { Summary of } \\
\text { evidence }\end{array}$ & 24 & $\begin{array}{l}\text { Summarize the main findings including the strength of evidence for each main outcome; } \\
\text { consider their relevance to key groups (e.g., healthcare providers, users, and policy makers) }\end{array}$ & $3-5$ \\
\hline Limitations & 25 & $\begin{array}{l}\text { Discuss limitations at study and outcome level (e.g., risk of bias), and at review-level } \\
\text { (e.g., incomplete retrieval of identified research, reporting bias) }\end{array}$ & $4-5$ \\
\hline Conclusions & 26 & $\begin{array}{l}\text { Provide a general interpretation of the results in the context of other evidence, and implications } \\
\text { for future research }\end{array}$ & $4-5$ \\
\hline
\end{tabular}

FUNDING

Funding 27 Describe sources of funding for the systematic review and other support 1 (e.g., supply of data); role of funders for the systematic review

From: Moher D, Liberati A, Tetzlaff J, Altman DG, The PRISMA Group. Preferred reporting items for systematic reviews and meta-analyses: The PRISMA Statement. PLoS Med 2009;6:e1000097 